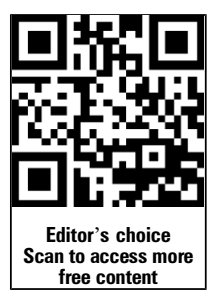
published online only. To view please visit the journal online (http://dx.doi.org/10.1136/ thoraxjnl-2015-206933)

For numbered affiliations see end of article.

\section{Correspondence to}

Dr Samuel Rhedin, Infectious Diseases Unit, Department of Medicine Solna, Karolinska Institutet and Karolinska University Hospital, Stockholm 171 76, Sweden; samuel.rhedin@ki.se

Received 16 February 2015 Revised 6 May 2015 Accepted 25 May 2015 Published Online First 15 June 2015

\title{
Respiratory viruses associated with community- acquired pneumonia in children: matched case-control study
}

\author{
Samuel Rhedin, ${ }^{1}$ Ann Lindstrand, ${ }^{2,3}$ Annie Hjelmgren, ${ }^{1}$ Malin Ryd-Rinder, ${ }^{4}$ \\ Lars Öhrmalm, ${ }^{1}$ Thomas Tolfvenstam, ${ }^{1,2}$ Åke Örtqvist, ${ }^{1,5}$ Maria Rotzén-Östlund, ${ }^{6,7}$ \\ Benita Zweygberg-Wirgart, ${ }^{6,7}$ Birgitta Henriques-Normark, ${ }^{6,7}$ Kristina Broliden, $^{1}$ \\ Pontus Naucler ${ }^{1}$
}

\begin{abstract}
Background Community-acquired pneumonia (CAP) is the leading cause of death in children worldwide and a substantial proportion of childhood CAP is caused by viruses. A better understanding of the role of virus infections in this condition is needed to improve clinical management and preventive measures. The aim of the study was therefore to assess the association between specific respiratory viruses and childhood CAP.

Methods A case-control study was conducted during 3 years in Stockholm, Sweden. Cases were children aged $\leq 5$ years with radiological CAP. Healthy controls were consecutively enrolled at child health units during routine visits and matched to cases on age and calendar time. Nasopharyngeal aspirates were obtained and analysed by real-time PCR for 15 viruses. Multivariate conditional logistic regression was used to account for coinfections with other viruses and baseline characteristics.

Results A total of 121 cases, of which 93 cases met

\section{Key messages}

What is the key question?

- What is the role of virus infections in community-acquired pneumonia in children?

What is the bottom line?

- Infection with respiratory syncytial virus, metapneumovirus and influenza virus infections were highly associated with community-acquired pneumonia in children.

\section{Why read on?}

- We performed a carefully designed case-control study that points out metapneumovirus as a new important target for the prevention of childhood pneumonia.
\end{abstract} the WHO criteria for radiological pneumonia, and 240 controls were included in the study. Viruses were detected in $81 \%$ of the cases $(n=98)$ and $56 \%$ of the controls ( $n=134)$. Influenza virus, metapneumovirus and respiratory syncytial virus were detected in $60 \%$ of cases and were significantly associated with CAP with ORs $>10$. There was no association with parainfluenza virus, human enterovirus or rhinovirus and coronavirus and bocavirus were negatively associated with CAP.

Conclusions Our study indicates viral CAP is an underestimated disease and points out hMPV as a new important target for the prevention of childhood CAP.

\section{INTRODUCTION}

Community-acquired pneumonia (CAP) is the leading cause of death in children aged $\leq 5$ years worldwide. ${ }^{1}$ A substantial proportion of childhood CAP is estimated to be caused by viruses, yet viral CAP is a condition that only recently is gaining increased attention. ${ }^{2}{ }^{3}$ Successful vaccination programmes against Haemophilus influenzae and Streptococcus pneumoniae have decreased the mortality and incidence of bacterial CAP, and it is likely that the relative importance of viral CAP will increase. ${ }^{4} \mathrm{~A}$ better understanding of the contribution of specific respiratory viruses in childhood
CAP is needed to improve clinical management and preventive measures.

Human adenovirus (HAdV), human bocavirus (HBoV), human coronavirus (HCoV) enterovirus (EV), influenza virus (Flu), metapneumovirus (hMPV), parainfluenza virus (PIV) and respiratory syncytial virus (RSV) infections have all been associated with childhood CAP. ${ }^{2}$ However, the majority of studies have been descriptive and case series of hospitalised patients and hence only provide a lowgrade level of evidence. ${ }^{2}$ Few case-control studies have investigated the association between viruses and childhood CAP and most of these studies have been done in low-income countries that might not represent the epidemiological pattern of highincome countries, or they used hospital-based controls that might bias the results. ${ }^{5-9}$ Moreover, childhood CAP is difficult to diagnose. The Integrated Management of Childhood Illness (IMCI) diagnostic guidelines for the clinical diagnosis of CAP, developed by the WHO, have been important to reduce mortality, yet they lack sensitivity and specificity and might introduce misclassification bias in epidemiological studies. ${ }^{10}$ The gold standard today is diagnosis based on radiographic findings, which is the preferred method of case definition in epidemiological studies. ${ }^{11}$ 
Advances in molecular diagnostic methods have increased the sensitivity of viral detection and led to discovery of novel viruses that cannot be detected by traditional virus isolation. ${ }^{12}$ Real-time PCR is a sensitive method that has been widely introduced in the routine clinical management in high-income countries. However, the clinical significance of a real-time PCR detection is obscured by extensive asymptomatic detection in children. ${ }^{13}$ This underscores the importance of representative controls as a reference when assessing the impact of respiratory viruses on CAP.

The primary aim of the study was to assess the association between specific respiratory viruses and childhood CAP. A secondary aim was to investigate the clinical presentation of different respiratory virus infections in children.

\section{METHODS}

\section{Study design}

A matched case-control study was conducted in Stockholm, Sweden, between September 2011 and March 2014, thus covering three winter seasons. No sampling was performed during summers. Notably, vaccination with pneumococcal conjugate vaccines (PCVs) in the child immunisation programme had been in place in the study setting since October 2007 (Prevenar 7 was replaced by Prevenar 13 in January 2010). Cases were children aged $\leq 5$ years with radiographic evidence of CAP (defined by a primary radiologist) enrolled at the paediatric emergency room or inpatient wards (within $48 \mathrm{~h}$ following admission) at Sachs' Children and Youth Hospital, South General Hospital and Astrid Lindgren Children's Hospital, Huddinge in Stockholm, Sweden. To reduce misclassification bias, all chest radiographs were retrospectively reviewed according to the WHO guidelines (endpoint alveolar consolidation or pleural effusion) by an independent senior paediatric radiologist. ${ }^{11}$

Controls were randomly selected from an ongoing study on carriage of S. pneumoniae in children. In this study, healthy children are consecutively sampled at child health units in Stockholm County during routine visits for regular check-ups or vaccination within the national childhood immunisation programme (covering $>99 \%$ of the population). ${ }^{14}$ Reported respiratory symptoms within the last 7 days were recorded, but were not an exclusion criteria. Up to two controls were matched to each case on calendar time ( \pm 14 days) and age ( \pm 6 months). If eligible controls were not found, intervals were expanded to \pm 30 days and \pm 12 months.

A standardised questionnaire was used to collect information regarding baseline characteristics in both study groups and cases also underwent a clinical examination at the time of enrolment. Tachycardia was defined as a heart rate of $\geq 160$ beats/min (bpm) in children aged $<1$ years and $\geq 120 \mathrm{bpm}$ in children aged $\geq 1$ years. Hypoxaemia was defined as peripheral oxygen saturation $<90 \%$ by pulse oximetry. Tachypnoea was defined as a respiratory rate of $\geq 60$ breaths $/ \mathrm{min}$ in children aged $<2$ months, $\geq 50$ breaths/min in children aged 2-12 months and as $\geq 40$ breaths $/ \mathrm{min}$ in children aged $>1$ year. Fever was defined as a body temperature $\geq 38.0^{\circ} \mathrm{C}$. Data on management and outcome of the cases were collected from the medical records. Severity of disease was defined according to the IMCI guidelines developed by the $\mathrm{WHO}^{15}$ and the respiratory index of severity in children (RISC) score was calculated based on Swedish growth standards. ${ }^{16}{ }^{17}$ Informed consents were collected from the guardians before enrolment.

\section{Sampling and microbiological analyses}

Nasopharyngeal aspirates were collected with an identical technique in both study groups. ${ }^{13}$ The samples were stored at $6^{\circ} \mathrm{C}-8^{\circ} \mathrm{C}$ during the day of sampling and subsequently frozen at $-80^{\circ} \mathrm{C}$. After thawing, a standardised real-time PCR assay was performed for the following 15 viruses at the accredited (ISO 15189:2012) Microbiological Laboratory at Karolinska University Hospital: HAdV, HBoV, HCoV (species HKU1, NL63, OC43 and 229E), EV, Flu (A, A(H1N1)pdm09 and B), hMPV, PIV 1-3, rhinovirus (RV), RSV (A and B). ${ }^{18}$ Single agent real-time PCRs were used for most viruses, nevertheless duplex real-time PCRs were used for PIV 1 and 3, for PIV 2 and $\mathrm{HCoV} 229 \mathrm{E}$ and for RSV A and B. Due to cross-reactivity between RV and EV, samples positive for both viruses were analysed with an in-house real-time PCR for EV. ${ }^{19}$ Cycle threshold (CT) values were recorded as an inverse estimate of viral load, yet all samples were also dichotomously coded as positive or negative. $^{18}$

\section{Data analysis}

Data were analysed in STATA V.12.0. Mann-Whitney U test was used for continuous data and Fisher's exact test or $\chi^{2}$ test was used for categorical data as appropriate. Conditional logistic regression was used to compare differences in baseline characteristics and the presence of viruses between cases and controls. To account for confounding by coinfections and differences in baseline characteristics between cases and controls, a multivariate conditional logistic regression model was constructed that included variables that had $\mathrm{p}$ values $<0.1$ in initial univariate analyses. A backward elimination approach was then performed based on likelihood ratio tests. Data were presented as ORs and 95\% CI. Due to high frequency of coinfections the initial matching strategy generated an unexpectedly large number of strata when adjusting for coinfections and resulted in large drift of the ORs (see online supplementary table S1). To account for that, individual matching sets were broken and instead study subjects were group-matched according to season (spring, fall, winter), year $(2011,2012,2013)$ and age $(<1$ and $\geq 1$ year), generating 18 strata. Separate analyses were performed for cases with pneumonia verified by a primary radiologist and for children with chest radiographs meeting the criteria by the WHO for epidemiological studies. The results of the first analysis represent the clinical reality of paediatricians and the second is according to gold standard.

\section{RESULTS}

\section{Baseline characteristics}

A total of 123 cases were enrolled during the study period. Two cases were excluded due to incomplete sampling. Data were not collected on non-participating study subjects. The research staff involved in enrolment approximate that $10 \%$ of parents to cases and $50 \%$ of parents to controls declined to participate in the study, mainly due to fear of discomfort for the child or lack of time. The expanded matching criteria had to be applied in 52 controls and for one case no eligible controls were found, hence 121 cases and 240 matched controls were included in the analyses. Ninety-three cases had presence of alveolar consolidation or pleural effusion on chest radiographs, consistent with the WHO criteria. Underlying diseases were more common among cases than controls (24\% compared with $4 \%$ of controls, $\mathrm{p}<0.001$ ) and $18 \%$ of the cases suffered from asthma or reactive airway disease (table 1).

A larger proportion of the cases was on current treatment with antibiotics $(13 \%$ compared with $1 \%$ of controls, $\mathrm{p}<0.001)$ or had received antibiotics during the last year $(46 \%$ and $28 \%$, respectively, $\mathrm{p}<0.01)$. Moreover, smoking among parents was more common in cases, whereas controls were more likely to 
Table 1 Baseline characteristics of study subjects

\begin{tabular}{|c|c|c|c|}
\hline Characteristic & $\begin{array}{l}\text { Cases } \\
(n=121) \\
n(\%)^{*}\end{array}$ & $\begin{array}{l}\text { Controls } \\
(n=240)\end{array}$ & $\mathrm{p}$ Value \\
\hline Age, months, median (IQR) & $21(15-33)$ & $19(11-28)$ & 0.97 \\
\hline Male sex & $72(60)$ & $120(50)$ & 0.12 \\
\hline $\begin{array}{l}\text { No. of children in household, } \\
\text { median (IQR) }\end{array}$ & $2(1-2)$ & $2(1-3)$ & 0.39 \\
\hline Attending daycare & $91(75)$ & $175(73)$ & 0.77 \\
\hline Breastfeeding & $20(17)$ & $47(20)$ & 0.39 \\
\hline$\geq 1$ parent smoking & $23(19)$ & $24(10)$ & 0.01 \\
\hline Chronic diseases & $28(24)$ & $9(4)$ & $<0.001$ \\
\hline $\begin{array}{l}\text { Asthma and reactive airway } \\
\text { disease }\end{array}$ & $21(18)$ & $4(2)$ & $<0.001$ \\
\hline Othert & 7 (6) & $5(2)$ & 0.09 \\
\hline Ongoing antibiotic treatment & $15(13)$ & $2(1)$ & $<0.001$ \\
\hline Antibiotic treatment last year & $55(46)$ & $67(28)$ & 0.002 \\
\hline Influenza vaccination last year & $10(9)$ & $1(0.4)$ & 0.004 \\
\hline Visit abroad last 3 months & $14(12)$ & $53(22)$ & 0.02 \\
\hline University degree of $\geq 1$ parent & $70(58)$ & $166(69)$ & 0.03 \\
\hline
\end{tabular}

have parents with a university degree and also more likely to have been travelling abroad within the last 3 months $(p=0.01$, $\mathrm{p}=0.03$ and $\mathrm{p}=0.02$, respectively).

\section{Viruses associated with CAP}

One or more viruses were detected in 98 (81\%) of the cases and 134 of the controls $(56 \% ; \mathrm{p}<0.001$; table 2$)$. RSV $(n=39$, $32 \%)$, hMPV $(n=28,23 \%)$ and RV $(n=28,23 \%)$ were the most common viruses among cases, whereas RV $(n=64,27 \%), \mathrm{HBoV}$ $(n=50,21 \%)$ and $\mathrm{HCoV}(n=28,12 \%)$ were the most commonly detected viruses in the controls. In univariate analyses, HAdV $(p=0.05)$, Flu $(p=0.03)$, hMPV $(p<0.001)$ and RSV $(\mathrm{p}<0.001)$ were significantly associated with CAP (table 2 and figure 1). In contrast, negative associations with CAP were seen for $\mathrm{HCoV}(p=0.03)$ and $\mathrm{HBoV}(p=0.04)$. A multivariate regression model was constructed, accounting for coinfection with multiple viruses and differences in baseline characteristics. RSV (OR $=21.3$, 95\% CI 8.3 to 54.4), hMPV (OR=14.9, 95\% CI 5.4 to 41.2$)$ and Flu (OR=13.8, 95\% CI 2.5 to 76.6$)$ had the highest ORs for CAP (table 2), combined being present in $60 \%$ of the cases. The significant association between HAdV and CAP disappeared in adjusted analyses $(\mathrm{OR}=1.4,95 \% \mathrm{CI}$ 0.5 to 3.9 ), whereas a negative association with $\mathrm{CAP}$ for $\mathrm{HCoV}$ $(\mathrm{OR}=0.2,95 \% \mathrm{CI} 0.0$ to 0.6$)$ and $\mathrm{HBoV}(\mathrm{OR}=0.3,95 \% \mathrm{CI}$ 0.1 to 0.8 ) was still present. In the analyses restricted to cases with radiological CAP consistent with WHO criteria $(n=93)$, the same significant associations were seen as in the analyses of all patients and there were only minor differences in the OR point estimates (table 2). To assess potential effect modification by age, multivariate conditional logistic regression analyses were performed for the most frequently detected viruses with the virus and age $(<1$ or $\geq 1$ year) included as binary variables together with an interaction term (age category multiplied with the virus). No significant effect modification by age was observed $(p=0.68, p=0.55$ and $p=0.62$ for hMPV, RSV and RV, respectively). The results were similar when age was categorised as $\leq 2$ and $>2$ years.
CT values for each virus were compared between cases and controls as an inverse estimate of viral load (figure 2). Cases positive for hMPV, RV and RSV had significantly lower CT values as compared with controls $(\mathrm{p}<0.01, \mathrm{p}=0.02$ and $\mathrm{p}<0.01$, respectively).

Of the 121 cases, $60(50 \%)$ had a single infection and 38 (31\%) had coinfections. In 31 cases (26\%) two viruses were detected, five cases (4\%) had three detected viruses, one case (1\%) had four detected viruses and in one case (1\%) five viruses were detected. Coinfections were seen in $50(21 \%)$ of the controls, with two viruses detected in $36(15 \%)$, three viruses detected in $11(5 \%)$, four viruses detected in one and five viruses detected in two (1\%) controls. In fact, all viruses except for RSV and Flu were predominantly detected as a coinfection in the cases (see online supplementary table S2). The most common virus pairs among cases were $\mathrm{HAdV} / \mathrm{RV}(\mathrm{n}=7), \mathrm{HAdV} /$ hMPV $(n=5), \mathrm{HBoV} / \mathrm{RSV}(\mathrm{n}=5)$ and hMPV/RV $(n=5)$. Flu, hMPV and RSV appeared to follow a seasonal distribution with peaks during winter/spring (see online supplementary figure S1). Flu tended to be more common during the winter season 2012/ $2013(p=0.07)$, whereas no difference in detection rates between the seasons was observed for RSV or hMPV.

\section{Clinical presentation in relation to viral findings}

Tachycardia, increased respiratory rate and fever were the most commonly observed clinical signs seen in $85 \%, 72 \%$ and $72 \%$ of the cases, respectively (table 3 ). Wheezing was noted in $41 \%$ of the cases and tended to be associated with detection of HBoV $(p=0.08)$ and to be negatively associated with HAdV and $\mathrm{HCoV}(\mathrm{p}=0.06$ and $\mathrm{p}=0.08$, respectively). Ninety-two $(76 \%)$ cases were admitted to inpatient wards for a median of 3 days, three patients were transferred to the paediatric intensive care unit and none of the children died during their hospitalisation. Antibiotic treatment was started on 115 (95\%) cases, of these $45(37 \%)$ received parenteral antibiotics. Seventy-seven (64\%) cases received inhalation therapy. As part of routine management nasopharyngeal bacterial cultures were collected from 10 cases, all were positive for one or more bacteria: $H$. influenzae $(\mathrm{n}=6)$, S. pneumoniae $(\mathrm{n}=5)$, Moraxella catharrhalis $(\mathrm{n}=5)$. Mycoplasma pneumoniae was detected by PCR in two of 26 tested cases. Five cases had radiographic evidence of pleural effusion. One out of 29 tested cases had a positive blood culture (positive for S. pneumoniae). This patient also had S. pneumoniae in the nasopharynx, tested positive for RSV and HCoV and had a massive infiltrate in the lower left lobe. He had received two doses of Prevenar 13 and serotyping revealed a non-vaccine type (serotype 38 ) of $S$. pneumoniae.

$\mathrm{C}$ reactive protein (CRP) analyses were ordered in 118 of 121 cases with a median of $73 \mathrm{mg} / \mathrm{L}$. HBoV, EV and hMPV were associated with low CRP $(p=0.04, p=0.04$ and $p=0.02$ respectively). The median RISC score was 1 and a RISC score of $\geq 3$ was negatively associated with detection of RV $(p=0.02)$. Severe pneumonia according to the clinical IMCI guidelines was observed in $48(40 \%)$ cases and was negatively associated with detection of RV $(p=0.04)$. Seventeen cases did not meet the IMCI criteria for CAP. Yet, 13 of these were classified as radiological CAP according to the WHO guidelines in the independent radiological revision.

\section{DISCUSSION}

The role of respiratory viruses in childhood CAP is not fully understood. To address this issue, we set up a matched casecontrol study with strict definitions of CAP based upon radiological findings. Controls were selected to represent the source 
Table 2 Viral detections in cases and controls

\begin{tabular}{|c|c|c|c|c|c|c|c|c|}
\hline \multirow[b]{2}{*}{ Detected virus } & \multicolumn{4}{|c|}{ All patients } & \multicolumn{4}{|c|}{ WHO radiological pneumonia } \\
\hline & $\begin{array}{l}\text { Cases } \\
(n=121) \\
n(\%)\end{array}$ & $\begin{array}{l}\text { Controls } \\
(n=240)\end{array}$ & $\begin{array}{l}\text { Unadjusted } \\
\text { ORs }(95 \% \mathrm{CI})\end{array}$ & Adjusted & $\begin{array}{l}\text { Cases } \\
(n=93) \\
n(\%)\end{array}$ & $\begin{array}{l}\text { Controls } \\
(n=220)\end{array}$ & $\begin{array}{l}\text { Unadjusted } \\
\text { ORs }(95 \% \mathrm{CI})\end{array}$ & Adjusted \\
\hline Adenovirus & $18(15)$ & $17(7)$ & 2.1 (1.0 to 4.3 ) & $1.4(0.5$ to 3.9$)$ & $12(13)$ & $17(8)$ & 1.7 (0.8 to 3.9$)$ & $1.1(0.4$ to 3.4$)$ \\
\hline Bocavirus & $14(12)$ & $50(21)$ & $0.5(0.3$ to 1.0$)$ & $0.3(0.1$ to 0.8$)$ & $12(13)$ & $46(21)$ & $0.6(0.3$ to 1.2$)$ & $0.3(0.1$ to 0.9$)$ \\
\hline Coronavirus (any) & $6(5)$ & $28(12)$ & $0.3(0.1$ to 0.9$)$ & $0.2(0.0$ to 0.6$)$ & $5(5)$ & $27(12)$ & $0.4(0.1$ to 1.0$)$ & $0.2(0.0$ to 0.8$)$ \\
\hline HKU1 & $3(2)$ & $16(7)$ & $0.3(0.1$ to 1.1$)$ & & $2(2)$ & $15(7)$ & 0.3 (0.1 to 1.2$)$ & \\
\hline NL63 & $1(1)$ & $3(1)$ & $0.6(0.1$ to 6.5$)$ & & $1(1)$ & $3(1)$ & 0.8 (0.1 to 8.5$)$ & \\
\hline $0 C 43$ & $1(1)$ & $8(3)$ & $0.2(0.0$ to 1.9$)$ & & $1(1)$ & $8(4)$ & 0.3 (0.0 to 2.3 ) & \\
\hline $229 \mathrm{E}$ & $1(1)$ & $2(1)$ & 0.7 (0.1 to 7.3$)$ & & $1(1)$ & $2(1)$ & 0.9 (0.1 to 10.2$)$ & \\
\hline Enterovirus & $2(2)$ & $7(3)$ & 0.5 (0.1 to 2.9$)$ & & $1(1)$ & $7(3)$ & 0.3 (0.0 to 3.0$)$ & \\
\hline Influenza (any) & $8(7)$ & $4(2)$ & $4.2(1.2$ to 14.5$)$ & 13.8 (2.5 to 76.6$)$ & $6(6)$ & $4(2)$ & $4.2(1.1$ to 15.7$)$ & $14.2(2.3$ to 87.1$)$ \\
\hline Influenza A & $4(3)$ & $1(0)$ & $7.3(0.8$ to 66.2$)$ & & $3(3)$ & $1(0)$ & 7.4 (0.8 to 71.9$)$ & \\
\hline H1N1 & $2(2)$ & $3(1)$ & $1.4(0.2$ to 9.0$)$ & & $1(1)$ & $3(1)$ & $1.0(0.1$ to 9.4$)$ & \\
\hline Influenza B & $2(2)$ & - & - & & $2(2)$ & - & - & \\
\hline Metapneumovirus & $28(23)$ & $11(5)$ & $6.5(3.0$ to 14.1$)$ & 14.9 (5.4 to 41.2$)$ & $17(18)$ & $10(5)$ & 4.8 (2.0 to 11.2$)$ & $10.8(3.5$ to 33.6$)$ \\
\hline Parainfluenza (any) & $3(2)$ & $7(3)$ & $0.9(0.2$ to 3.6$)$ & & $2(2)$ & $6(3)$ & 0.9 (0.2 to 4.3$)$ & \\
\hline Parainfluenza 1 & $1(1)$ & $1(0)$ & $2.6(0.2$ to 43.5$)$ & & - & - & - & \\
\hline Parainfluenza 3 & $2(2)$ & $6(3)$ & $0.7(0.1$ to 3.4$)$ & & $2(2)$ & $6(3)$ & 0.9 (0.2 to 4.3$)$ & \\
\hline $\begin{array}{l}\text { Respiratory syncytial } \\
\text { (RS) virus }\end{array}$ & $39(32)$ & $14(6)$ & 10.1 (4.8 to 21.2 ) & 21.3 (8.3 to 54.4 ) & $30(32)$ & $13(6)$ & 9.0 (4.1 to 19.3 ) & $15.8(6.1$ to 40.8$)$ \\
\hline Rhinovirus & $28(23)$ & $64(27)$ & $0.8(0.5$ to 1.4$)$ & & $20(22)$ & $60(27)$ & 0.7 (0.4 to 1.3$)$ & \\
\hline Positive any virus & $98(81)$ & $134(56)$ & $3.4(2.0$ to 5.9$)$ & & $72(77)$ & $122(55)$ & 2.8 (1.6 to 4.9$)$ & \\
\hline Single infection & $60(50)$ & $84(35)$ & $3.5(2.0$ to 6.1$)$ & & $46(49)$ & $72(33)$ & $3.0(1.6$ to 5.4$)$ & \\
\hline Coinfection & $38(31)$ & $50(21)$ & $3.4(1.8$ to 6.5$)$ & & $26(28)$ & $50(23)$ & $2.5(1.3$ to 5.0$)$ & \\
\hline Two pathogens & $31(26)$ & $36(15)$ & & & $22(24)$ & $36(16)$ & & \\
\hline Three pathogens & $5(4)$ & $11(5)$ & & & $2(2)$ & $11(5)$ & & \\
\hline Four pathogens & $1(1)$ & $1(0)$ & & & $1(1)$ & $1(0)$ & & \\
\hline Five pathogens & $1(1)$ & $2(1)$ & & & $1(1)$ & $2(1)$ & & \\
\hline
\end{tabular}

population, sampling and collection of baseline data were standardised and hence we believe that the results have high validity.

Viruses were detected in $>80 \%$ of the cases. This is in line with Jain $e t a l^{3}$ who recently reported detection of viruses in $73 \%$ of children hospitalised with CAP in a large prospective study in the USA. RSV, hMPV and Flu were present in $60 \%$ of the cases and were highly associated with CAP with adjusted OR $>10$. Importantly, no positive association was observed between CAP and infections with RV, HBoV, EV nor with any of the $\mathrm{HCoV}$. This needs to be considered when interpreting viral
Figure 1 Viral PCR positivity in cases and controls. Relative number of real-time PCR detections for cases (grey, $n=121$ ) and controls (white, $\mathrm{n}=240$ ). Number above bars indicates percentage of positive detections within group. p Values calculated with conditional logistic regression.

${ }^{*} p<0.05,{ }^{* *} p<0.01$ and ${ }^{* * *} p<0.001$.

\section{Viral PCR Positivity in the Nasopharynx of Children $\leq 5$ Years with Community-Acquired Pneumonia and Healthy Controls}

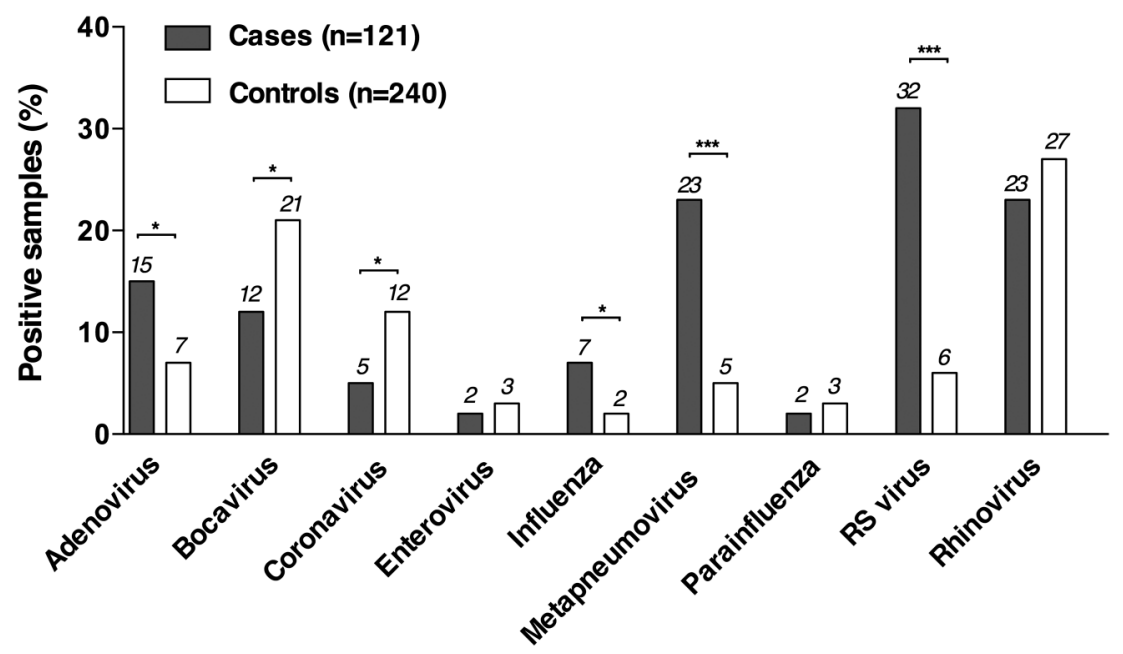


Figure 2 PCR cycle threshold (CT) values in cases and controls. Box plot of CT values for all PCR-positive cases (grey) and controls (white) sorted by virus. $p$ Values calculated with MannWhitney U test. ${ }^{*} p<0.05,{ }^{* *} p<0.01$ ， $* * * p<0.001$.
PCR CT-values in Cases and Controls

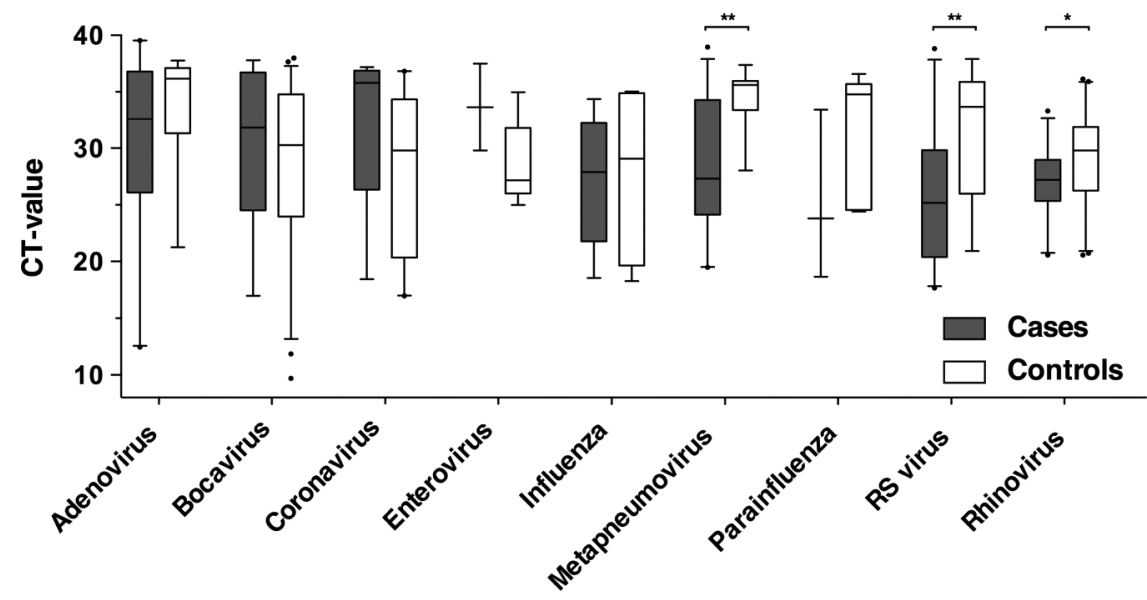

findings with similar real-time PCR detection methods in children with CAP.

Recent publications suggest that hMPV accounts for extensive morbidity in children with an estimated hospitalisation rate of 1 in 1000 in children aged $\leq 5$ years in the USA. ${ }^{20}$ The virus is a member of the paramyxoviridae family (subfamily pneumovirinae), together with RSV, hence it shares many similarities with RSV both in terms of virus structure and clinical presentation. ${ }^{21}$ The epidemiology is characterised by a seasonal distribution largely varying in incidence from year to year; however in this study, hMPV was detected at high rates during all three respiratory seasons. ${ }^{22}$ In the northern hemisphere, the highest incidence is seen during late winter and early spring. ${ }^{22}$ Infection with hMPV is associated with both upper and lower respiratory tract infections and the virus has been shown to successfully replicate in pneumocytes of macaques, but the role in CAP is not fully understood. ${ }^{22}{ }^{23}$ Being detected in more than a fifth of all

Table 3 Clinical signs and management of cases

\begin{tabular}{|c|c|}
\hline Clinical signs & n (\%) \\
\hline Tachycardia & $94(85)$ \\
\hline Tachypnoea & $81(72)$ \\
\hline Fever $\left(\geq 38.0^{\circ} \mathrm{C}\right)$ & $86(72)$ \\
\hline Chest indrawing & $61(59)$ \\
\hline Wheezing & $49(41)$ \\
\hline Hypoxaemia & $27(23)$ \\
\hline RISC score, median (range) & $1(-2-5)$ \\
\hline Severe pneumonia (IMCI classification) & $48(40)$ \\
\hline$C$ reactive protein $\mathrm{mg} / \mathrm{L}$, median (range) & 73 (nd-433) \\
\hline Treatment and management & $\mathrm{n}(\%)$ \\
\hline Started on antibiotics & $115(95)$ \\
\hline Received inhalation therapy & $77(64)$ \\
\hline Oxygen treatment & $53(44)$ \\
\hline Parenteral fluid given & $51(42)$ \\
\hline Steroid treatment & $17(14)$ \\
\hline Transfer to paediatric intensive care unit & $3(2)$ \\
\hline Admission to inpatient ward & $92(76)$ \\
\hline Days of admission, median (range) & $3(1-20)$ \\
\hline \multicolumn{2}{|c|}{$\begin{array}{l}\text { Tachypnoea defined as respiratory rate } \geq 60 \text { in patients aged }<3 \text { months, } \geq 50 \text { in } \\
\text { children aged } 3-12 \text { months and } \geq 40 \text { in children aged }>1 \text { year. Tachycardia defined as } \\
\text { heart rate } \geq 160 \text { in children aged }<1 \text { year and } \geq 120 \text { in children aged }>1 \text { year, } \\
\text { Hypoxaemia defined as peripheral } O_{2} \text { saturation }<90 \% \text {. } \\
\text { IMCl, Integrated Management of Childhood Illness; nd, non-detectable; RISC, } \\
\text { respiratory index of severity in children. }\end{array}$} \\
\hline
\end{tabular}

children with CAP with a significant over-representation among cases, our study suggests the virus to play an important role in childhood CAP. Moreover, hMPV was associated with lower CRP levels, which is indicative of viral CAP. ${ }^{24}$

Flu and RSV were also associated with CAP and only seldom detected in controls with detection rates concordant with Jain et $a l^{3}$ who detected RSV and Flu in 28\% and 7\%, respectively, in hospitalised children with CAP in the USA. This indicates that a substantial burden of CAP can be attributed to RSV, whereas the role of Flu seems to be less important in this condition.

Viruses were detected in more than half of the control subjects, the most common were RV, HBoV and HCoV. The high detection rate can partly be explained by our decision not to exclude controls with respiratory symptoms reported within the last 7 days. However, exclusion of controls with respiratory tract infection would make the control group less representative of the source population and would likely overestimate the contribution of viruses in $\mathrm{CAP}^{25}$ Prolonged shedding of viruses such as $\mathrm{HBoV}$ that has been reported for up to 10 weeks is likely to reduce the clinical specificity of real-time PCR. ${ }^{26}$

Interestingly, $\mathrm{HBoV}$ and $\mathrm{HCoV}$ were negatively associated with CAP. Negative interaction between viruses, such as between Flu and RV, has been reported. ${ }^{27}$ Many infections are followed by an excessive proinflammatory response including accumulation of immune cells. It can thus be speculated whether the immune responses elicited by the more pathogenic microbes in the symptomatic children were eliminated or protected against infection by these presumably less pathogenic viruses.

HAdV was not significantly associated with CAP in adjusted analyses and was rather frequently detected in controls. HAdV is a pathogen that for long has been known to cause CAP, $^{2}$ but the virus has a stable configuration and has been reported to persist in lymphatic tissue for weeks. ${ }^{28}$ The prevalence of PIV and EV was low in both cases and controls. PIV has previously been associated with childhood CAP, in contrary to our results. ${ }^{3} 5$ 7-9 29 The real-time PCRs for PIV are monitored by yearly participation in quality assessment panels. Nevertheless, as with all PCRs there is always a risk of escape by unknown mutations.

High viral load of certain viruses has been associated with severe respiratory disease in children. ${ }^{12}$ In our data, CT values for hMPV, RSV and RV were significantly lower in cases than in controls indicating a higher viral load. However, the estimation of viral load is associated with uncertainty in nasopharyngeal sampling and we did not have an internal control to account for sample quantity. 
A difference in educational level and smoking among parents was observed between cases and controls. To adjust for these differences, parental smoking and educational level were included in the initial multivariate regression models but did not affect the point estimates. To further investigate socioeconomic differences between the groups, we obtained data on purchase power from the child healthcare services in Stockholm County based on postal codes of the study subjects. ${ }^{14}$ The proportion of families with low purchase power in the whole of Stockholm County was $20.9 \%$ (index 1.0). The residential areas of cases had a lower purchase power compared with controls (index 1.16 vs $0.75, \mathrm{p}<0.001)$. Since we did not have individual data on purchase power we did not include it in the multivariate model. Hence, we cannot rule out some residual socioeconomic confounding in the analyses.

To minimise misclassification bias, all chest radiographs were revised by an independent senior radiologist and a subanalysis of cases meeting the WHO criteria for radiological CAP in children was done generating similar results as the full-scale analysis.

It is difficult to obtain valid samples to define whether CAP is caused by bacteria in children; blood cultures are rarely positive and representative respiratory samples are difficult to obtain. ${ }^{30}$ We did not systematically obtain bacterial sputum samples or blood cultures, hence it is not clear to what extent cases were coinfected with bacteria. We did perform pneumococcal bacterial cultures on all nasopharyngeal samples where $32 \%$ of the cases and $33 \%$ of the controls were positive $(p=0.747)$, which as previous studies show that pneumococcal isolation in the nasopharynx in children with CAP is of limited use to determine aetiology. ${ }^{31}$ Several studies both in mice and in humans indicate that certain viral infections predispose for bacterial superinfection. ${ }^{32-34} \mathrm{~A}$ recent study of lung aspirates in children with CAP in the Gambia showed S. pneumoniae in $90 \%$ of the samples, yet this was prior to introduction of PCV and most detected pneumococci were serotypes included in the PCV. ${ }^{35}$ They did not find any hMPV which might indicate that the aetiology of CAP in high- and low-income countries differ. ${ }^{10}$ This is further supported by the low detection rate of hMPV (3\%) in the study by Berkley et $a l^{5}$ on Kenyan children with severe CAP. Yet, it is also possible that viral detection in the nasopharynx might not be fully representative of findings in the lung.

Our study indicates viral CAP is an underestimated disease and points out hMPV as a new important target for the prevention of childhood CAP. Better diagnostic methods are warranted to distinguish viral from bacterial CAP, which will clarify if these viral infections cause CAP on their own or merely predispose for bacterial coinfection. This will be pivotal for decision making regarding antibiotic treatment.

\footnotetext{
Author affiliations

${ }^{1}$ Department of Medicine Solna, Infectious Diseases Unit, Karolinska Institutet and Karolinska University Hospital, Stockholm, Sweden

${ }^{2}$ The Public Health Agency of Sweden, Stockholm, Sweden

${ }^{3}$ Department of Public Health Sciences, Karolinska Institutet, Stockholm, Sweden ${ }^{4}$ Department of Clinical Science and Education, Karolinska Institutet, Sachs' Children and Youth Hospital, South General Hospital, Stockholm, Sweden

${ }^{5}$ Department of Communicable Disease and Control, Stockholm County Council, Stockholm, Sweden

${ }^{6}$ Department of Clinical Microbiology, Karolinska University Hospital, Stockholm, Sweden

${ }^{7}$ Department of Microbiology, Tumor and Cell Biology, Karolinska Institutet, Stockholm, Sweden
}

Twitter Follow Samuel Rhedin at @rhedinsamuel

Acknowledgements We would like to acknowledge paediatric resident Dr Sara Leeb, pediatric radiologist Dr Helen Stålemark, medical students Karolin Petersson,
Henrik Hurtigh and Hritul Karim, research nurses Kerstin Jämtberg, Carita Krokstrand, Marie Olander-Carlson, Eva Sjögren and Karin Grunditz-Melin, as well as the staff at Sachs' Children and Youth Hospital, at Karolinska Children's Hospital Huddinge and at the Karolinska Microbiological Laboratory in Stockholm, above all Pia Andersson.

Contributors SR coordinated enrolment of case patients at the study sites, collected and interpreted data from patient history files of the case patients, performed statistical analyses and wrote the initial draft of the manuscript; PN designed and conceptualised the study and supervised collection of samples, statistical analyses and writing of the manuscript; $\mathrm{AH}$ supervised data collection at one of the study sites, critically re-evaluated medical histories, performed a pilot analysis of the initial data and critically reviewed and revised the manuscript; $A L$, $\mathrm{BH}-\mathrm{N}$ and $\AA \mathrm{O}$ designed the data collection instruments, managed and supervised data collection of the control subjects, interpreted sociodemographic and clinical data of the control subjects and reviewed and revised the manuscript; LÖ, MR-Ö, $\mathrm{TT}$ and BZ-W designed the standardised sampling protocol, conducted, supervised and interpreted the microbiological analyses and reviewed and revised the manuscript from a clinical microbiological point of view and MR-R supervised data collection at one of the study sites, critically re-evaluated medical histories and interpreted clinical signs of infection of the case patients and reviewed and revised the manuscript from a paediatric point of view. KB designed and supervised the study, interpreted data analyses and critically reviewed and revised the manuscript; all authors approved the final version of the manuscript.

Funding The study was supported by grants from the Stockholm County Council, the Shizu Matsumura Donation, the Swedish Society of Medicine and the Swedish Childhood Cancer Foundation.

Competing interests MR-R has been clinical investigator in an epidemiological study on rotavirus with Glaxo Smith Kline and Sanofi Pasteur MSD 2008-2009 and a clinical study on RotaTeq vaccine for Sanofi Pasteur MSD 2013-2014.

\section{Patient consent Obtained.}

Ethics approval Regional Ethical Review Board in Stockholm (ref 2011/879-31/1).

Provenance and peer review Not commissioned; externally peer reviewed.

Data sharing statement As to date, we do not hold any unpublished data from the study. Nevertheless, we have plans on performing additional analyses on the samples collected.

\section{REFERENCES}

1 Walker CL, Rudan I, Liu L, et al. Global burden of childhood pneumonia and diarrhoea. Lancet 2013;381:1405-16.

2 Ruuskanen 0, Lahti $\mathrm{E}$, Jennings LC, et al. Viral pneumonia. Lancet 2011;377:1264-75.

3 Jain S, Williams DJ, Arnold SR, et al. Community-acquired pneumonia requiring hospitalization among US children. N Engl J Med 2015;372:835-45.

4 Lindstrand A, Bennet R, Galanis I, et al. Sinusitis and pneumonia hospitalization after introduction of pneumococcal conjugate vaccine. Pediatrics 2014;134: e1526-36.

5 Berkley JA, Munywoki P, Ngama M, et al. Viral etiology of severe pneumonia among Kenyan infants and children. JAMA 2010;303:2051-7.

6 Fry AM, Lu X, Chittaganpitch M, et al. Human bocavirus: a novel parvovirus epidemiologically associated with pneumonia requiring hospitalization in Thailand. J Infect Dis 2007;195:1038-45.

7 Mathisen M, Strand TA, Valentiner-Branth $P$, et al. Respiratory viruses in nepalese children with and without pneumonia: a case-control study. Pediatr Infect Dis J 2010;29:731-5.

8 Singleton RJ, Bulkow LR, Miernyk K, et al. Viral respiratory infections in hospitalized and community control children in Alaska. J Med Virol 2010;82:1282-90.

9 Wolf DG, Greenberg D, Shemer-Avni Y, et al. Association of human metapneumovirus with radiologically diagnosed community-acquired alveolar pneumonia in young children. J Pediatr 2010;156:115-20.

10 Wingerter SL, Bachur RG, Monuteaux MC, et al. Application of the world health organization criteria to predict radiographic pneumonia in a US-based pediatric emergency department. Pediatr Infect Dis J 2012;31:561-4.

11 Cherian T, Mulholland EK, Carlin JB, et al. Standardized interpretation of paediatric chest radiographs for the diagnosis of pneumonia in epidemiological studies. Bull World Health Organ 2005;83:353-9.

12 Jartti T, Söderlund-Venermo M, Hedman K, et al. New molecular virus detection methods and their clinical value in lower respiratory tract infections in children. Paediatr Respir Rev 2013:14:38-45.

13 Rhedin S, Lindstrand A, Rotzén-Östlund M, et al. Clinical utility of PCR for common viruses in acute respiratory illness. Pediatrics 2014;133:e538-45.

14 Martin H, Frenzel L, Fassih N, et al. Barnhälsovård - Annual report by Stockholm County Child Health Centers. 2013.

15 International Child Health Review Collaboration. Pocket book of hospital care for children. 2nd edn. Geneva: World Health Organization, 2013. 
16 Reed C, Madhi SA, Klugman KP, et al. Development of the Respiratory Index of Severity in Children (RISC) score among young children with respiratory infections in South Africa. PLOS ONE 2012;7:e27793.

17 Wikland KA, Luo ZC, Niklasson A, et al. Swedish population-based longitudinal reference values from birth to 18 years of age for height, weight and head circumference. Acta Paediatr 2002;91:739-54.

18 Tiveljung-Lindell A, Rotzén-Ostlund M, Gupta S, et al. Development and implementation of a molecular diagnostic platform for daily rapid detection of 15 respiratory viruses. J Med Virol 2009;81:167-75.

19 Nijhuis M, van Maarseveen N, Schuurman R, et al. Rapid and sensitive routine detection of all members of the genus enterovirus in different clinical specimens by real-time PCR. J Clin Microbiol 2002;40:3666-70.

20 Edwards KM, Zhu Y, Griffin MR, et al. Burden of human metapneumovirus infection in young children. N Engl J Med 2013;368:633-43.

21 Panda S, Mohakud NK, Pena L, et al. Human metapneumovirus: review of an important respiratory pathogen. Int J Infect Dis 2014;25:45-52.

22 Williams J, Halburnt-rush LL, Ed M, et al. Human metapneumovirus and lower respiratory tract disease in otherwise healthy infants and children. $N$ Engl J Med 2004;250:443-50.

23 Kuiken $T$, van den Hoogen BG, van Riel D a J, et al. Experimental human metapneumovirus infection of cynomolgus macaques (Macaca fascicularis) results in virus replication in ciliated epithelial cells and pneumocytes with associated lesions throughout the respiratory tract. Am J Pathol 2004;164:1893-900.

24 Virkki $\mathrm{R}$, Juven $\mathrm{T}$, Rikalainen $\mathrm{H}$, et al. Differentiation of bacterial and viral pneumonia in children. Thorax 2002;57:438-41.

25 Deloria-Knoll M, Feikin DR, Scott JA, et al. Identification and selection of cases and controls in the Pneumonia Etiology Research for Child Health project. Clin Infect Dis 2012;54(Suppl 2):S117-23.
26 Martin ET, Fairchok MP, Kuypers J, et al. Frequent and prolonged shedding of bocavirus in young children attending daycare. J Infect Dis 2010;201: 1625-32.

27 Cowling BJ, Fang VJ, Nishiura $\mathrm{H}$, et al. Increased risk of noninfluenza respiratory virus infections associated with receipt of inactivated influenza vaccine. Clin Infect Dis 2012;54:1778-83.

28 Kalu SU, Loeffelholz M, Beck E, et al. Persistence of adenovirus nucleic acids in nasopharyngeal secretions: a diagnostic conundrum. Pediatr Infect Dis J 2010;29:746-50.

29 Do Carmo Debur M, Raboni SM, Flizikowski FBZ, et al. Immunohistochemical assessment of respiratory viruses in necropsy samples from lethal non-pandemic seasonal respiratory infections. J Clin Pathol 2010;63:930-4.

30 Juven T, Mertsola J, Waris M, et al. Etiology of community-acquired pneumonia in 254 hospitalized children. Pediatr Infect Dis J 2000;19:293-8.

31 Bogaert D, De Groot R, Hermans PWM. Streptococcus pneumoniae colonisation: the key to pneumococcal disease. Lancet Infect Dis 2004;4:144-54.

32 Weinberger DM, Klugman KP, Steiner $\mathrm{C}$ a, et al. Association between respiratory syncytial virus activity and pneumococcal disease in infants: a time series analysis of US hospitalization data. PLoS Med 2015;12:e1001776.

33 Kukavica-Ibrulj I, Hamelin M-E, Prince G a, et al. Infection with human metapneumovirus predisposes mice to severe pneumococcal pneumonia. J Virol 2009;83:1341-9.

34 Madhi S, Ludewick H. Pneumococcal coinfection with human metapneumovirus J Infect Dis 2006;193:1236-43.

35 Howie SR, Morris GA, Tokarz R, et al. Etiology of severe childhood pneumonia in the Gambia, west Africa, determined by conventional and molecular microbiological analyses of lung and pleural aspirate samples. Clin Infect Dis 2014;59:682-5. 